\title{
Role of immunoglobulin E and mast cells in murine models of asthma
}

\section{S.I. Mayr ${ }^{1}$, \\ R.I. Zuberi ${ }^{1}$ \\ and F.-T. $\mathrm{Liu}^{2}$}

\author{
${ }^{1}$ La Jolla Institute for Allergy and Immunology, La Jolla, CA, USA \\ ${ }^{2}$ Department of Dermatology, University of California, Davis, \\ Sacramento, CA, USA
}

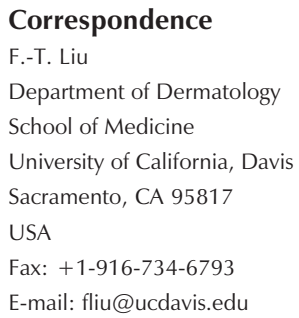

Presented at the XVII Annual Meeting of the Federação de Sociedades de Biologia Experimental, Salvador, BA, Brazil, August 28-31, 2002.

\begin{abstract}
Immunoglobulin $\mathrm{E}$ (IgE) and mast cells are believed to play important roles in allergic inflammation. However, their contributions to the pathogenesis of human asthma have not been clearly established. Significant progress has been made recently in our understanding of airway inflammation and airway hyperresponsiveness through studies of murine models of asthma and genetically engineered mice. Some of the studies have provided significant insights into the role of $\operatorname{IgE}$ and mast cells in the allergic airway response. In these models mice are immunized systemically with soluble protein antigens and then receive an antigen challenge through the airways. Bronchoalveolar lavage fluid from mice with allergic airway inflammation contains significant amounts of IgE. The IgE can capture the antigen presented to the airways and the immune complexes so formed can augment allergic airway response in a high-affinity IgE receptor (FceRI)dependent manner. Previously, there were conflicting reports regarding the role of mast cells in murine models of asthma, based on studies of mast cell-deficient mice. More recent studies have suggested that the extent to which mast cells contribute to murine models of asthma depends on the experimental conditions employed to generate the airway response. This conclusion was further supported by studies using FceRI-deficient mice. Therefore, IgE-dependent activation of mast cells plays an important role in the development of allergic airway inflammation and airway hyperresponsiveness in mice under specific conditions. The murine models used should be of value for testing inhibitors of IgE or mast cells for the development of therapeutic agents for human asthma.
\end{abstract}

Human asthma is a chronic disease characterized by allergic airway inflammation with increased mucus production and lung epithelium remodeling, intermittent airway obstruction and airway hyperresponsiveness (AHR) (1). The role of inflammation in the pathogenesis and disease progression of asthma has gained increased attention in recent years. In the most recent definition of
Key words

- Asthma

- IgE

- Mast cells

- Airway hyperresponsiveness ...................... asthma by the National Heart and Lung Institute and World Health Organization it was stated that "asthma is a chronic inflammatory disorder of the airways in which many cells play a role, in particular mast cells, eosinophils and T-lymphocytes". While a variety of clinical studies have led to our increased understanding of molecular and cellular mechanisms of allergic airway in- 
flammation, the use of murine models has been extremely beneficial in this regard. In this review, we will discuss the functions of immunoglobulin $\mathrm{E}$ ( $\mathrm{IgE}$ ) and mast cells in allergic airway inflammation in murine asthma models.

\section{Mast cells: roles as effector and regulatory cells}

Mast cells have long been regarded as an important cell type involved in allergic airway inflammation. These cells are derived from pluripotent $\mathrm{CD} 34+$ hematopoietic progenitor cells in the bone marrow. They are released into the circulation as morphologically unidentified precursors and after being recruited to different tissues they complete their differentiation under the influence of stem cell factor and other locally produced cytokines. The heterogeneity of mast cells is based on the concept that they mature and differentiate after settling into specific tissues with certain microenvironmental factors (2). Ordinarily mast cells are distributed throughout the connective tissue, where they are often situated adjacent to blood and lymphatic vessels and beneath epithelial surfaces that are exposed to environmental antigens (2). Mast cells are more numerously present in the airway mucosa of asthmatics compared to normal individuals, and there is a progressive mast cell degranulation from the lamina propria toward the lumen in the airways of asthmatics. Mast cells release their mediators via two different mechanisms, firstly by antigen-specific $\operatorname{IgE}$ antibodies that bind to mast cells via the highaffinity IgE receptor (FcERI). These cell surface-bound IgE molecules can subsequently become cross-linked upon binding to the antigen, resulting in mast cell activation and release of a plethora of proinflammatory molecules. Secondly, mast cells can be stimulated nonimmunologically by direct triggers such as neuropeptides, basic compounds, complement components, and certain drugs, e.g., opiates and contrast media (2).

Mast cells can release a group of preformed and newly synthesized mediators, which are heterogeneous in their potency and biological function. The spasmogenic and vasoactive mediators (histamine, leukotrienes, prostaglandins) induce immediate hypersensitivity reactions such as direct spasmogenic activity on the airway smooth muscle leading to acute bronchoconstriction, bronchial mucosa edema, and mucus secretion. Other chemical mediators (cytokines and chemokines) can contribute to acute- and late-phase inflammatory responses that promote infiltration of other leukocytes, including eosinophils, to sites of inflammation. Released and newly synthesized proteases (chymase, tryptase and carboxypeptidase A) might provoke airway remodeling (3). The fact that mast cells are activated in human asthma is supported by the presence of histamine and tryptase in bronchoalveolar lavage fluid (BALF) of patients with chronic asthma (4).

Preformed granules, released about $5 \mathrm{~min}$ after the antigen contact, contain histamine, proteoglycans (heparin, chondroitin sulfate E), and neutral proteases (chymase, tryptase, carboxypeptidase A) in various compositions. Lipid-derived mediators include the metabolites of arachidonic acid by cyclooxygenase (prostaglandins, thromboxanes) and lipoxygenase (leukotrienes) which are produced about 5 to $30 \mathrm{~min}$ after the antigen contact. Various cytokines (IL-1, $-3,-4,-5$, $-6,-8,-10,-13,-16$, TNF- $\alpha$, and TGF- $\beta$ ) and chemokines (MIP-1- $\alpha$, MCP-1) are synthesized and secreted by mast cells about an hour after the antigen contact. The numerous cytokines and chemokines have complex and partly redundant functions in acute- and latephase inflammatory responses.

Mast cells also play a regulatory role in the immune response. Because of their ability to secrete various mediators and cytokines, mast cells can exert influence on $\mathrm{T}$ cell and B cell functions. First, mast cells are 
a major source of cytokines (e.g., IL-4, -10 and -13 ) that can signal naive and memory $\mathrm{T}$ cells to preferentially differentiate into the Th2 subset. It has indeed been shown that mast cells can signal naive and memory $T$ cells to preferentially differentiate into Th2 cells (5). Second, mast cells can present antigen to $\mathrm{T}$ cells (6). Third, human mast cells can directly stimulate IgE synthesis in B cells (7).

\section{IgE and IgE-dependent mast cell activation in allergic inflammation of the airways}

$\operatorname{IgE}$ and mast cells are part of the IgEassociated immune response. The role of $\operatorname{IgE}$ and IgE-dependent mast cell activation in asthma is underlined by the close correlation of increased serum IgE levels and the prevalence of asthma (8). Asthma can also result after sensitization to multiple and various allergens. Furthermore, in clinical trials, patients treated with monoclonal anti-IgE antibody showed a decrease in symptom scores accompanied by a significant decrease or discontinuation of steroid use (9). In mice, it has been reported that IgE-mediated activation of mast cells enhances pulmonary responsiveness to cholinergic stimulation (10). These findings present evidence for a role of IgE-dependent mast cell activation as a trigger for allergic airway inflammation.

\section{Murine models}

In recent years, significant progress has been made in our understanding of cellular and molecular components involved in airway inflammation and AHR, especially through studies in murine models of asthma. The use of genetically engineered mice with altered expression or deletion of relevant gene products has been particularly useful. Various cellular and molecular components, such as cytokines, chemokines, cell adhesion molecules, as well as peptide and lipid inflammatory mediators, have been identified in this regard (11-13).

In the murine models of asthma, experimental mice are generally immunized intraperitoneally with a soluble antigen, such as ovalbumin (OVA), of different concentrations plus alum as adjuvant. One time immunization is usually sufficient for immunologic response (increase in antigen-specific $\operatorname{IgE}$ ), whereas an immunization without alum has to be administered several times for similar responses. The antigen challenge is performed at least 14 days later in order to have proper B cell switching. There are different ways to do the airway antigen challenge, either after aerosolized OVA once a day for several consecutive days or intranasally on alternate days, after which in vivo and in vitro data are collected (Figure 1).

The application of murine models in the drug development for asthma has various advantages. Firstly, it serves preclinically for the validation of targets by testing the effectiveness of agonists/antagonists as well as genetically engineered mice. Secondly, the postclinical application can help elucidate the mechanisms of drug action and the development of improved drugs.

\section{Role of IgE in murine models}

It has been reported that in mice germinal centers are formed in the parenchyma of inflamed lungs following airway antigen challenge and these contain IgG- and IgE-producing plasma cells, shown to produce the corresponding isotypes, when isolated from the lungs and then cultured in vitro (14). Locally produced IgE as well as circulating $\operatorname{IgE}$ is likely to sensitize mast cells in the airways.

In $\mathrm{BALB} / \mathrm{c}$ mice immunized with OVA as antigen plus alum as adjuvant and challenged with OVA aerosol, the concentrations of eosinophils and IgE in BALF increased with the number of aerosol challenges. In contrast, with the antigen chal- 
lenge finished, the eosinophil concentration immediately started a steep decline over time, reaching the pre-challenge eosinophil concentration seven days later. However, the levels of total IgE and OVA-specific IgE in BALF remained elevated until 15 days after the last antigen challenge. We reasoned that IgE upon contact with OVA could form IgEOVA immune complexes, which could potentiate the airway response. Indeed, IgE immune complexes were detected in BALF of mice sensitized with antigen systemically and then challenged with the same antigen intranasally. Furthermore, when OVA-sensitized mice were challenged with TNPOVA-IgE or TNP-OVA, it was noted that there was a higher concentration of IL-4 accumulated in the BALF of mice exposed to the immune complex. This increased response to the immune complex was not observed in FceRI-deficient mice. The results provide evidence that $\operatorname{IgE}$ is secreted locally in a murine model of asthma and can capture the antigen presented to the airways. These immune complexes are able to augment the allergic airway response in an FceRI-dependent manner. Thus, $\operatorname{IgE}$ present in airway secretions may facilitate antigen-mediated allergic airway inflammation (15).
However, there are controversial reports on the role of $\operatorname{IgE}$ in the murine models. There are studies supporting the importance of IgE by demonstrating that anti-IgE antibody when administered before the antigen challenge is able to inhibit eosinophil infiltration (16). Furthermore, athymic mice that were passively sensitized with $\operatorname{IgE}$ and treated with IL-5 exhibited increased airway reactivity (17). However, allergic airway inflammation and AHR can be elicited in mice in the absence of $\operatorname{IgE}(18,19)$ or all classes of antibodies (20). The conclusion drawn from these various and differing results was that IgE plays an important role in the development of airway inflammation and AHR under experimental conditions in which the eosinophil inflammation is relatively low (21).

\section{Mast cells can amplify airway reactivity and features of chronic inflammation in murine asthma models}

As mast cell activation has been shown to be a source of induction of eosinophil infiltration as well as AHR $(10,22)$, it is conceivable that mast cells play an important role in the airway response in murine models of
Figure 1. Murine model of asthma. Mice are immunized intraperitoneally (ip) with ovalbumin (OVA) plus alum as adjuvant. The antigen challenge is performed at least 14 days later, either with aerosolized OVA once a day for several consecutive days or intranasally on alternate days. Three or twenty-four hours after that in vivo and in vitro data are collected. BALF, bronchoalveolar lavage fluid.

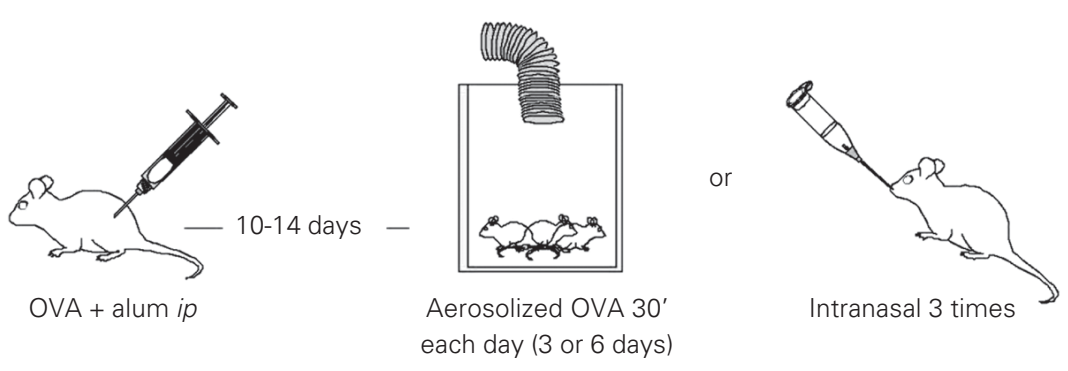

Responses

Peribronchial eosinophil infiltrations Increased eosinophils in BALF Increased Th2 cytokines in BALF Increased lgE levels in serum Develop airway hyperresponsiveness Mucus occlusion of the airway lumen

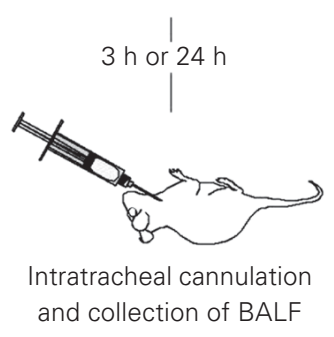


asthma. The role of mast cells in allergic airway inflammation has been investigated in a series of studies taking advantage of the existence of $\mathrm{W} / \mathrm{Wv}$ mast cell-deficient mice. There are studies that support the role of mast cells in these models, demonstrating that mast cell deficiency results in attenuated eosinophil airway inflammation $(23,24)$. However, a number of studies opposed mast cell participation in allergic airway inflammation and AHR (25-28).

Kobayashi et al. (29) noted that W/Wv mice sensitized to OVA exhibited a clearly reduced AHR compared to normal congenic mice when challenged by OVA through the airways. However, W/Wv mice developed AHR that was comparable to normal mice when the frequency and the dose of the antigen challenge were increased. They proposed that AHR can be developed by two distinct cellular mechanisms, one being mast cell dependent and eosinophil dependent, and the other being only mast cell dependent. Hence AHR can be induced by different mechanisms and only certain protocols would enlist mechanisms that involve IgE-mediated mast cell activation. Likewise, Williams and Galli (30) noted that W/Wv mice developed significantly reduced responses when the mice were immunized with OVA in the absence of adjuvant and then challenged with OVA intranasally. In contrast, W/Wv mice that were sensitized with OVA in alum and then challenged with aerosolized OVA exhibited airway responses similar to normal mice.

In accordance with these reports, FceRIdeficient mice exhibited reduced airway responses only under experimental conditions where immunization or antigen challenge was suboptimal. We found that FceRI-deficient mice developed reduced airway eosinophil inflammation compared to wild-type mice, when they were sensitized with OVA in the absence of adjuvant and then challenged with OVA through the airways. OVAsensitized FceRI-deficient mice also showed reduced airway inflammation when they were challenged with OVA intranasally, but not when they were challenged with nebulized OVA (31). These findings support the importance of IgE-dependent mast cell activation in airway inflammation in murine models of asthma. However, the extent to which mast cells contribute to airway inflammation and AHR in mice is highly dependent on the experimental model used to generate the airway response.

In normal mice, IgE-mediated activation of mast cells enhances pulmonary responsiveness to cholinergic stimulation but the same was not achieved in mast cell-deficient mice. The deficiency can be restored when the mast cell-deficient mice are reconstituted with mast cells (10). We found that mice immunized and challenged with OVA through the airways did not exhibit bronchoconstriction when they received a subsequent OVA provocation at a higher concentration. However, these mice developed AHR to methacholine challenge. Significantly, FceRI-deficient mice exhibited significantly reduced AHR compared to wild-type mice under these conditions (31). The results support the notion that IgE-dependent mast cell activation can result in AHR probably through certain mediators, which themselves are not potent enough to cause a detectable bronchial response, but will potentiate the response to methacholine challenge. The localization of mast cells in the lungs in mice is mainly in the tracheal and main bronchial submucosal areas (32), thus the release of mast cell mediators triggered by antigen provocation and inhaled methacholine takes place at the effector sites. FceRI-deficient mice only show the smooth muscle contraction through methacholine provocation, whereas the wild-type mice are highly sensitized and respond with a mast cell-dependent reaction, after antigen provocation plus the cholinergic stimulation of the smooth muscles.

The studies presented in this review sup- 
port the view that IgE and mast cells play an important role in the development of allergic airway inflammation and AHR in mice. However, it is evident that the extent to which $\operatorname{IgE}$ and mast cells contribute to the murine models of asthma depends on the experimental conditions employed to generate the airway response. The studies have provided insights into how IgE and mast cells may contribute to human asthma. Moreover, the models used should be of value for testing inhibitors of $\mathrm{IgE}$ or mast cells for development of therapeutic agents for human asthma.

\section{References}

1. Arm JP \& Lee TH (1992). The pathobiology of bronchial asthma. Advances in Immunology, 51: 323-382.

2. Metcalfe DD, Baram D \& Mekori YA (1997). Mast cells. Physiological Reviews, 77: 1033-1079.

3. Galli SJ \& Costa JJ (1995). Mast-cell-leukocyte cytokine cascades in allergic inflammation. Allergy, 50: 851-862.

4. Broide DH, Gleich GJ, Cuomo AJ, Coburn DA, Federman EC, Schwartz LB \& Wasserman SI (1991). Evidence of ongoing mast cell and eosinophil degranulation in symptomatic asthma airway. Journal of Allergy and Clinical Immunology, 88: 637-648.

5. Hofstra CL, Van Ark I, Nijkamkp FP \& Van Oosterhout AJ (1999). Antigen-stimulated lung CD4+ cells produce IL-5, while lymph node $\mathrm{CD} 4+$ cells produce Th2 cytokines concomitant with airway eosinophilia and hyperresponsiveness. Inflammation Research, 48: 602612.

6. Tkaczyk C, Villa I, Peronet R, David B \& Mecheri S (1999). FcepsilonRI-mediated antigen endocytosis turns interferon-gammatreated mouse mast cells from inefficient into potent antigen-presenting cells. Immunology, 97: 333-340.

7. Pawankar R, Okuda M, Yssel H, Okumura K \& Ra C (1997). Nasal mast cells in perennial allergic rhinitics exhibit increased expression of the Fc epsilonRI, CD40L, IL-4, and IL-13, and can induce IgE synthesis in B cells. Journal of Clinical Investigation, 99: 1492-1499.

8. Burrows B, Martinez FD, Halonen M, Barbee RA \& Cline MG (1989). Association of asthma with serum IgE levels and skin-test reactivity to allergens. New England Journal of Medicine, 320: 271-277.

9. Milgrom H, Fick Jr RB, Su JQ, Reimann JD, Bush RK, Watrous ML \& Metzger WJ (1999). Treatment of allergic asthma with monoclonal anti-IgE antibody. rhuMAb-E25 Study Group. New England Journal of Medicine, 341: 1966-1973.

10. Martin TR, Takeishi T, Katz HR, Austen KF, Drazen JM \& Galli SJ (1993). Mast cell activation enhances airway responsiveness to methacholine in the mouse. Journal of Clinical Investigation, 91: 1176-1182.

11. Wills-Karp M (1999). Immunologic basis of antigen-induced airway hyperresponsiveness. Annual Review of Immunology, 17: 255-281.

12. Corrigan CJ \& Kay AB (1992). T cells and eosinophils in the pathogenesis of asthma. Immunology Today, 13: 501-507.

13. Holt PG, Macaubas C, Stumbles PA \& Sly PD (1999). The role of allergy in the development of asthma. Nature, 402: B12-B17.

14. Chvatchko Y, Kosco-Vilbois MH, Herren S, Lefort J \& Bonnefoy JY (1996). Germinal center formation and local immunoglobulin E (IgE) production in the lung after an airway antigenic challenge. Journal of Experimental Medicine, 184: 2353-2360.

15. Zuberi RI, Apgar JR, Chen SS \& Liu FT (2000). Role for IgE in airway secretions: IgE immune complexes are more potent inducers than antigen alone of airway inflammation in a murine model. Journal of Immunology, 164: 2667-2673.
16. Coyle AJ, Wagner K, Bertrand C, Tsuyuki S, Bews J \& Heusser C (1996). Central role of immunoglobulin (lg) $E$ in the induction of lung eosinophil infiltration and Thelper 2 cell cytokine production: inhibition by a non-anaphylactogenic anti-IgE antibody. Journal of Experimental Medicine, 183: 1303-1310.

17. Hamelmann E, Oshiba A, Schwarze J, Bradley K, Loader J, Larsen GL \& Gelfand EW (1997). Allergen-specific IgE and IL-5 are essential for the development of airway hyperresponsiveness. American Journal of Respiratory Cell and Molecular Biology, 16: 674-682.

18. Mehlhop PD, van de Rijn M, Goldberg AB, Brewer JP, Kurup VP, Martin TR \& Oettgen HC (1997). Allergen-induced bronchial hyperreactivity and eosinophilic inflammation occur in the absence of IgE in a mouse model of asthma. Proceedings of the National Academy of Sciences, USA, 94: 1344-1349.

19. Hamelmann E, Cieslewicz G, Schwarze J, Ishizuka T, Joetham A, Heusser C \& Gelfand EW (1999). Anti-interleukin 5 but not anti-lgE prevents airway inflammation and airway hyperresponsiveness. American Journal of Respiratory and Critical Care Medicine, 160: 934-941.

20. Corry DB, Grunig G, Hadeiba H, Kurup VP, Warnock ML, Sheppard D, Rennick DM \& Locksley RM (1998). Requirements for allergeninduced airway hyperreactivity in T and B cell-deficient mice. Molecular Medicine, 4: 344-355.

21. Hamelmann E, Tadeda K, Oshiba A \& Gelfand EW (1999). Role of $\lg \mathrm{E}$ in the development of allergic airway inflammation and airway hyperresponsiveness - a murine model. Allergy, 54: 297-305.

22. Galli SJ (1997). Complexity and redundancy in the pathogenesis of asthma: reassessing the roles of mast cells and T cells. Journal of Experimental Medicine, 186: 343-347.

23. Kung TT, Stelts D, Zurcher JA, Jones H, Umland SP, Kreutner W, Egan RW \& Chapman RW (1995). Mast cells modulate allergic pulmonary eosinophilia in mice. American Journal of Respiratory Cell and Molecular Biology, 12: 404-409.

24. Ogawa K, Kaminuma O, Kikkawa H, Kameda R, Ikezawa K, Suko M, Okudaira H, Akiyama K \& Mori A (1999). Primary role of CD4+ T cells and supplemental role of mast cells in allergic pulmonary eosinophilia. International Archives of Allergy and Immunology, 120 (Suppl 1): $15-18$

25. Nogami $M$, Suko $M$, Okudaira $H$, Miyamoto $T$, Shiga J, Ito $M$ \& Kasuya S (1990). Experimental pulmonary eosinophilia in mice by Ascaris suum extract. American Review of Respiratory Disease, 141: 1289-1295.

26. Brusselle GG, Kips JC, Tavernier JH, van der Heyden JG, Cuvelier CA, Pauwels RA \& Bluethmann H (1994). Attenuation of allergic airway inflammation in IL-4 deficient mice. Clinical and Experimental Allergy, 24: 73-80.

27. Nagai H, Yamaguchi S, Maeda $Y$ \& Tanaka H (1996). Role of mast cells, eosinophils and IL-5 in the development of airway hyperre- 
sponsiveness in sensitized mice. Clinical and Experimental Allergy, 26: 642-647.

28. Takeda K, Hamelmann E, Joetham A, Shultz LD, Larsen GL, Irvin CG \& Gelfand EW (1997). Development of eosinophilic airway inflammation and airway hyperresponsiveness in mast cell-deficient mice. Journal of Experimental Medicine, 186: 449-454.

29. Kobayashi T, Miura T, Haba T, Sato M, Serizawa I, Nagai H \& Ishizaka K (2000). An essential role of mast cells in the development of airway hyperresponsiveness in a murine asthma model. Journal of Immunology, 164: 3855-3861

30. Williams CM \& Galli SJ (2000). Mast cells can amplify airway reactivity and features of chronic inflammation in an asthma model in mice. Journal of Experimental Medicine, 192: 455-462.

31. Mayr SI, Zuberi RI, Zhang M, de Sousa-Hitzler J, Ngo K, Kuwabara Y, Yu L, Fung-Leung WP \& Liu FT (2002). IgE-dependent mast cell activation potentiates airway responses in murine asthma models. Journal of Immunology, 169: 2061-2068.

32. Temann UA, Geba GP, Rankin JA \& Flavell RA (1998). Expression of interleukin 9 in the lungs of transgenic mice causes airway inflammation, mast cell hyperplasia, and bronchial hyperresponsiveness. Journal of Experimental Medicine, 188: 1307-1320. 